\title{
On the Confidential Education of Colleges and Universities under the Background of Emerging Engineering Education
}

\author{
Hu Xueli, Xi Qi, Qin Yanfeng, Peng Jianshan \\ Information Engineering University \\ Zhengzhou, 450001, China
}

\begin{abstract}
With the rapid development of information technology, it is urgent to promote confidential education at the confidential work is facing a severe situation and shoulders an arduous task. Under the new situation carrying out the disciplinary development of confidential and diploma education is a pioneering and important measure to strengthen the national secrecy work, which have great significance to the scientific development of confidential work. Emerging Engineering Education development make higher demands on the reform and development of China's higher engineering education, and the confidential education faces new challenges. This paper shed light on the relationship between the construction of emerging engineering education and the development of confidential education, and analyzed the problems in the current college education. Taking into account the construction of emerging engineering education, it also put forward some thoughts on the cultivating compound skilled talents who know well about law, and are good at management by following the principle of "theoretical guarantee, application-oriented, and advanced content”.
\end{abstract}

Keywords-confidential education; emerging engineering education; faculty; talent training; engineering ability

\section{INTRODUCTION}

As China advances in political, military, economic, scientific and technological fields, and digitalization, informationization, and networking grows fast, the struggle of confidentiality and theft is becoming increasingly severe. It is an arduous task to keep secret. Carrying out confidentialityrelated disciplines and academic education is a pioneering step to strengthen the national secrecy work under the new situation, and is of great significance to the scientific development of confidential work [1]. Emerging Engineering Education is a reform of China's engineering education based on the new requirements of national strategic development, the situation of international competition, and the new demands of moral and virtue education [2]. The emerging engineering education corresponds to the emerging industries and the new economic field. Different from the traditional engineering education, it puts forward new requirements for the training of engineering talents. It is worthy of consideration by the secrecy educators of higher education institutions that how to develop the secret education which is important for emerging engineering education, and how to seize the opportunity to ride the wave of technological innovation and the development of new industries.

\section{EMERging ENGINEERING EDUCATION AND CONFIDENTIAL EDUCATION}

In 2017, the Ministry of Education put forward the emerging engineering education that aims at driving industrialization by information technology. It centers on the development concept of "innovative, integrated and full-cycle engineering education”. As a result, the overall requirements for the development of professional disciplines in higher engineering education in China were made. In 2012, the secrecy management major was officially admitted in the "Undergraduate Profession Catalogue of General Colleges and Universities (2012)" as the "Special Specialty". The Central Secrecy Committee and the State Secrecy Bureau began stationing in different areas of the country, relying on computer science, information security, law, management and other disciplines, and fully integrate the secret professional colleges established by existing resources. These measures reflect that our country highly regard the training of secret professionals. The secrecy profession steps forward to actively respond to the real needs of higher education for national secrecy. So, what is the relationship between the construction of emerging engineering education and the development of confidential education?

\section{A. Background}

In the context of the new generation of information technology revolution, the new industrial revolution, and the integration of manufacturing and service industries, a new type of market-oriented economy with technology, application and model innovation as the core comes into being. Facing the new trends and new demands of economic development, technology and industrial development, the world's higher engineering education confronts new opportunities and challenges. The reform and development of China's higher engineering education is also standing at a new historical starting point [3]. The emerging engineering education is put forward in this situation.

With the advent of the new industrial revolution, people have entered the information age as the information technology with computer and communication as the core keeps growing, 
bringing new technologies such as mobile Internet, big data, cloud computing, artificial intelligence, and robots. Today, with the increasingly integrated world economy and the fastchanging high-tech means, the struggle of secrecy and theft in technology is also intensifying. The secrecy work faces a more severe situation and shoulders arduous tasks. Therefore, to do a good job in confidentiality under the new situation, we must have priority, strengthen policies, and firmly adhere to new ideas. In adapting to new industries and new technologies, the secret education shares something in common with emerging engineering education.

\section{B. Interdisciplinary fusion}

Compared with traditional engineering education, emerging engineering education emphasizes the practicality, mix and comprehensiveness of disciplines, especially the integration of traditional industrial technologies with new technologies such as information communication, electronic control and software design. The emerging engineering highlights the interdisciplinary and comprehensive disciplines with a deep integration of multidisciplinary and multi-technology. As for the engineering education at Stanford University [4], students who are major in engineering also need to understand philosophy, and business students must also do engineering experiments. To be a great comprehensive university, rather than a polytechnic college, we need to maintain our diversity, and strike a balance among liberal arts, science, and engineering.

The confidential education of colleges and universities, whether it is the confidential management disciplines or the confidential curriculum content, involves computer science, information security, law, management, journalism, international politics, sociology and other disciplines. The secrecy discipline itself is typically interdiscipline, and has formed a series of key fields of scientific research and teaching, such as confidential science and technology, confidential management science, which conforms to the structural requirements of emerging engineering education in the development of disciplines.

\section{Training mode with engineering ability as the core}

Strengthen moral education and cultivate diversified innovative engineering talents to cope with changes and shape the future by inheriting and innovation, interdisciplinary, integration, coordinating and sharing. That is the connotation of the emerging engineering education [2]. Instead of traditional engineering talents, the future emerging industries and new economy need high-quality composite "new engineering” talents with strong engineering practical ability, innovation ability and international competitiveness [5].

It is pointed out in the "Guidance Professional Standards for Confidential Management of Colleges and Universities" [6] (Exposure Draft) that graduates of confidentiality management should have the ability to define confidential information, manage dynamically the classified information, review and utilization of the classified information, and inspect and troubleshooting, prevent leaking secrets, investigate and handle the leaks, and provide confidential training. So it is the basic requirement that confidential management professionals should maintain engineering capability. In conclusion, secrecy academic education coincides with emerging engineering education in the training of engineering ability.

\section{The Status Quo of the Development of Confidential ACADEMIC EDUCATION IN COLLEGES AND UNIVERSITIES}

The construction of emerging engineering education has brought both opportunities and challenges to the development of confidential education in colleges and universities. On the one hand, the confidential education has bright future as the state attaches great importance to confidentiality work, and provides a favorable external environment for the education. On the other hand, the espionage of Western countries runs rampant. So we are in badly need of relevant talents. At present, the secret education of higher education institutions is weak in profession, curriculum system, and teaching staff building. Additionally, we are still feeling the way in the training mode of compound secret talents, which is a huge challenge for the development of college secret education.

\section{A. Imperfect construction of confidentiality profession}

Seen from the science and technology covered by the current confidential work and its content, the construction of confidentiality profession is incomplete. For example, there are different levels and types of classified information in political, military, economic, and other fields. This requires further classification of confidential education objects in different fields to determine different talent training programs. It is obvious that only a secret profession construction is far more enough.

\section{B. Lack of professional secret teacher}

Confidentiality academic education is an emerging interdisciplinary subject. From the perspective of discipline construction, the teaching team including academic leaders and key teachers should be composed by secret professionals engaged in disciplinary research. Currently, there are only parttime teachers of relevant professions, and few are specialized in secret disciplines. These teachers do not entertain the knowledge of professions involved in confidential education, and are short of confidential work experience and advanced secrecy concepts. At present, there is a lack of composite secret teachers in college education.

\section{Lack of confidential engineering practice}

The confidential education of colleges and universities is still at a groping stage. The previous secret education is mainly based on theory with auxiliary secrecy technology. Many universities have not yet built experimental platforms for the training of secret talents. What' more, because of the particularity of confidentiality, it is difficult for students to have access to the confidential practice of the classified units.

\section{Lack of attention from the teaching subject}

Judging from the employment of graduates of local colleges and universities, only a few students have engaged in confidentiality-related work. However, the current employment 
situation directly affects students' attitude towards confidentiality profession and subjects.

As there is no secrecy major in military academies, the confidential education mainly relies on confidential courses and confidential lectures. Whereas, the confidential discipline cannot attract enough attention from students as it has limited class hours and lacks of systematic curriculum system. Students deem that the master of it or not won't matter, and getting a passing grade is enough.

\section{REFLECTIONS ON THE CONFIDENTIAL EDUCATION UNDER THE BACKGROUND OF EMERGING ENGINEERING EDUCATION}

The progress of emerging engineering education has provided a good opportunity for confidentiality education in colleges and universities. And the confidentiality education should take advantage of it to achieve better and faster development.

\section{A. Complete curriculum system construction based on demands}

The curriculum construction is the foundation of the teaching in colleges and universities. Schools should develop their curriculum system of confidential academic education by taking in to consideration the different knowledge structures and teaching situation and focusing on the needs of the classified units such as the state and the military, and the requirements of "enhance engineering education and keep eye on the actual needs of the combined engineering" in the construction of "emerging engineering". The curriculum setting should focus on two aspects. First, the "confidential practice" should be added to the content of the curriculum which includes the "secure management" and "secure technology" basic theory. There should be fewer but better professional major curricula with some related minor courses. Second, the curriculum can break out the professional boundaries and integrate content across disciplines, thus promoting the cultivation of compound secret talents.

\section{B. Establish a team of confidential professional teachers}

We will follow the cross-curricular characteristic of the emerging engineering education, and the rule of confidential academic education to build a high-level secrecy teaching team with reasonable mix of full-time and part-time teachers. It is the basis for education to cultivate high-quality teaching team which should include at least the following three types of personnel: front-line personnel with high confidentiality management level, rich experience and advanced concepts; scientific and technical personnel who matters advanced confidential technology and follows the latest movements; core confidential teacher with high teaching, research and learning capabilities.

Through various incentives, mobilize the initiative of teachers to participate in confidential teaching, and keep passion in it. Introduce talents to enlarge the confidential teaching team. Employ outstanding graduates of secrecy, or high-level academic leaders and formulate special incentives. Attract front-line secret cadres and confidential experts with rich confidential work experience and certain academic research capabilities to take up part-time short-term teaching and research work. Launch the program to cultivate emerging engineering practical teachers, improve the training and reeducation system of secret teachers, and explore the training method of "academic education plus front-line practice". All these measures are expected to achieve the cultivation of the young core teachers, make it easier for teachers to go between colleges and organs and units to realize the rational use of resources.

\section{Exploring engineering secret talent training methods}

Under the backdrop of emerging engineering education, the confidential education should press ahead the construction of practical courses, and improve students' innovative ability and engineering practice ability in practice in accordance with the training objectives of new engineering science and technology talents.

1) Comply with the construction of emerging engineering and accelerate the construction of confidential experimental platform

Build a standardized, comprehensive and inclusive confidential experimental platform that truly combines theory with practice. A standardized, comprehensive experimental platform helps students form a systematic confidential knowledge system, deepen the understanding of the spying means under the informationization conditions, and improves students' security defense ability and practical operation ability. Whereas, a inclusive experimental platform provides experimental environment for students to learn independently, which contributes to students' innovative thinking and capability.

2) Take scientific research projects as the guide to foster students' engineering ability

Guide students to participate in researches on confidentiality and information security. Due to the particularity of confidentiality issues, it is not easy for students to access researches on these topics directly. Therefore, secretly-owned units and institutions involved should issue confidential scientific research open projects for students to participate in research projects. In this way, students can improve their ability to solve practical problems, and engineering capabilities.

3) Build a culture of confidentiality and strengthen the sense of confidentiality

On the basis of the education of "confidential culture", hold seminars for students and confidential training personnel to exchange ideas, and confidential knowledge contests, organize students to participate in confidential inspections of cooperative units, simulate confidential work, cultivate a sense of honor among confidential personnel, and strengthen students' acknowledgement and loyalty of confidential work.

4) Enrich the teaching methods by using informational teaching resources

Make full use of information teaching resources, and adopt diversified education such as flipped classroom, case teaching, situational teaching, experiential teaching, and innovative projects to build a secret education talent training mode that is 
driven by mission, demand-oriented, confidential and with effective methods.

\section{CONCLUSION}

The emerging engineering education puts engineering talents training in a strategic position, strengthens research on emerging engineering construction, explores the training methods of confidential talents, and accelerates the development of confidential academic education with new ideas and new requirements. In the light of the current development of domestic high-level secret education, this paper put forward some thoughts on curriculum setting, teaching team and engineering ability training, which may be beneficial to the college education.

\section{REFERENCES}

[1] Zheng Chonghui, Sun Jianguo. Construction and Management of the Practice Condition of Confidential Academic Education [J]. Secrecy Science and Technology. 2012(2)38-40.

[2] Zhong Denghua. Connotation and Action of New Engineering Construction [J]. Research in Higher Education of Engineering.2017 (3)1-6.

[3] Zou Xiaodong, Li Tuoyu, Zhang Wei et al. China's Manufacturing Power Strategy and Engineering Education Reform[J] .Research in Higher Education of Engineering,2016(3): 9-14.

[4] Hu Bo, Feng Hui, Han Weili et al. Accelerate the Construction of Emerging Engineering and Promote the Reform and Innovation of Engineering Education[J]. Fudan Education Forum,2017(2): 20-27.

[5] Liu Xuedong. New Thinking, New Curriculum: Stanford University General Education Reform [J]. Research on Education Tsinghua University, 2014(5):96-102.

[6] Wu Ting. Several Problems and Exploration in the Cultivation of Confidential Management Talents. Journal of Beijing Electronic Science and Technology Institute [J].2016(3) 19-22. 